Department of

Economics and Finance

Guglielmo Maria Caporale, Alessandro Girardi and Paolo Paesani

Quoted Spreads and Trade I mbalance Dynamics in the European Treasury Bond Market

December 2010 


\title{
Quoted Spreads and Trade Imbalance Dynamics in the European Treasury Bond Market
}

\author{
Guglielmo Maria Caporale \\ Brunel University, London \\ Alessandro Girardi \\ ISAE, Rome \\ Paolo Paesani \\ University of Rome “Tor Vergata”
}

November 2010

\begin{abstract}
Using high-frequency transaction data for the three largest European markets (France, Germany and Italy), this paper documents the existence of an asymmetric relationship between market liquidity and trading imbalances: when quoted spreads rise (fall) and liquidity falls (increases) buy (sell) orders tend to prevail. Risk-averse market-makers, with inventory-depletion risk being their main concern, tend to quote wider (narrower) spreads when they think bond appreciation is more (less) likely to occur. It is also found that the probability of being in a specific regime is related to observable bond market characteristics, stock market volatility, macroeconomic releases and liquidity management operations of the monetary authorities.
\end{abstract}

Keywords: Liquidity, trading activity, Treasury bond market, Europe, commonality

JEL Classification: G1, G15, C32, C33

Corresponding author: Professor Guglielmo Maria Caporale, Centre for Empirical Finance, Brunel University, West London, UB8 3PH, UK. Tel.: +44 (0)1895 266713. Fax: +44 (0)1895 269770. E-mail: GuglielmoMaria.Caporale@brunel.ac.uk 


\section{1 - Introduction}

Over the past few years a growing body of research has been devoted to analysing the market for government securities in Europe focusing on the dynamic relationship between trading activity and price movements (Cheung et al., 2005) and between yield dynamics and order flow (Menkveld et al., 2004), on the determination of the benchmark status among securities of similar maturity (Dunne et al., 2007), on the analysis of yield differentials between sovereign bonds (Beber et al., 2009), and on the process of price discovery in cash and future markets (Upper and Werner 2002) or in multiple cash markets (Caporale and Girardi, 2010).

With the aim of contributing to this literature, the present study focuses on the relationship between quoted spreads and trading imbalances and on its financial and macroeconomic determinants. While these issues have been extensively discussed in the case of the US stock market, no comparable analysis has been conducted to date in the case of European markets for government securities.

Our analysis is related to the strand of financial literature investigating the interaction between liquidity and trading activity. This interaction affects the process of price discovery (Brandt and Kavajecz, 2004), depends on the degree of financial integration (Hasbrouck and Seppi, 2001; Korajczyk and Sadka, 2008) and matters for regulatory purposes. From a practical point of view, as liquidity affects the cost and feasibility of dynamic trading strategies (Johnson, 2008), understanding what factors influence quoted spreads and trading imbalances is relevant for trading-strategy formulation purposes.

Working on a dataset containing high-frequency transaction data for nine benchmark medium-long term Treasury bonds over the period July 32006 - June 292007 (taken as representative of general market dynamics), we obtain the following main results. First, by estimating bivariate Markov-switching Vector Auto-Regressions (MS-VAR) for each bond in the sample, we find that dealers pay attention to the information revealed by order flows. In 
particular, we document the existence of an asymmetric relationship between quoted spreads and trading imbalances such that when liquidity is high (low) and quoted spreads narrow (wide), sell (buy) orders tend to prevail. For most bonds in the sample, we also find an intermediate state when orders tend to be balanced.

Second, after daily averaging intra-day probabilities extracted from the estimated MSVAR models, we investigate common potential determinants for the switches across states by random effect probit-estimation for longitudinal data. We find that the relationship between liquidity and trading imbalances is affected by financial and macroeconomic factors including: refinancing costs, bond and stock market volatility, changing business and macroeconomic climate and changing monetary policy stance.

The rest of the paper is organised as follows. Section 2 presents the data and some descriptive statistics. In Section 3 we investigate the dynamic interaction between quoted spreads and order flow imbalances at the individual bond level. Section 4 explores the role of common factors in explaining co-movements between these two market characteristics at an aggregate level. Section 5 offers some concluding remarks.

\section{2 - Data and measurement}

We use transaction-based data for benchmark Treasury bonds with maturities of 5, 10 and 32 years. The data are extracted from the MTS (Mercato Telematico dei Titoli di Stato) database. ${ }^{1}$ The MTS system is an example of quote-driven electronic order book markets for Government securities. Proposals are firm, immediately executable and aggregated in a limit order book. ${ }^{2}$ As in Dunne et al. (2007), we analyse the three largest European markets (Italy,

\footnotetext{
${ }^{1}$ For a detailed discussion of the MTS system, see Scalia and Vacca (1999) and Cheung et al. (2005), among others.

${ }^{2}$ Using Italian Government bond data, Coluzzi and Ginebri (2008) test several theoretical hypotheses about limit orders. In this paper, the focus is on commonalities driving the relationship between trading activity and quoted spreads for the European government bond market as a whole.
} 
France and Germany), which account for over 70 percent of the European secondary bond market. ${ }^{3}$ The dataset consists of tick-by-tick transaction data (prices and traded nominal volumes) matched with the bid-ask spread prevailing at the moment each transaction took place. The sample covers the period from 3 July 2006 to 29 June 2007. In terms of both its cross-sectional dimension and time span it is broadly comparable to that used by Cheung et al. (2005), D'Souza et al. (2007) and Dunne et al. (2007), among others. Based on data from opening hours of the MTS system (from 8:15 to 17:30 Central European Time, CET), Table 1 provides the list of bond codes along with information on issue dates, maturity dates and summary statistics on trading activity. ${ }^{4}$

[Table 1]

Following Goldreich et al. (2005) and Pasquariello and Vega (2009), our preferred indicator of liquidity is the quoted bid-ask spreads ( $q s p r$ ), defined as the difference between the best bid and best ask divided by mid-quote prices (equally weighted) averaged during half-hour time intervals. The trading imbalances indicator (oflw) is constructed as the aggregate volume of buyer- minus seller-initiated orders during half-hour intervals. ${ }^{5}$ Excess buy-side or sell-side order flows are closely related to trading costs as they represent aggregate pressure on the inventories of market makers (Chordia et al. 2002) and are likely to capture the arrival of new information (Brandt and Kavajecz, 2004). ${ }^{6}$

\footnotetext{
${ }^{3}$ According to Dunne et al. (2008), with an outstanding aggregate value of around 4,396 billion Euros in 2006, the European sovereign bond market is the world's largest market for debt securities and it exceeds the size of the US one by roughly 3 billion euros.

${ }^{4}$ While a government fixed income instrument becomes a benchmark security de jure once auctioned in the primary market, it becomes a benchmark bond de facto once its trading volume exceeds the one for the old benchmark.

${ }^{5}$ Using data with higher frequency (namely variables recorded at 5-minute intervals), the estimates of MS-VAR models failed to converge. This is due to the huge number of observations (up to 25,000 datapoints) when using 5-minute intervals.

${ }^{6}$ Unlike equity market studies, where the calculation of order flows is commonly based on classification
} 
Table 2 provides some descriptive statistics for $q s p r$ and oflw. Although the sample means of average order flows vary considerably across bonds, the ratio $\left|o f l w_{M}\right| / o f l w_{S D}$ is bounded within tight intervals (less than 0.3 ), suggesting that market makers control their inventories so as to avoid excessive imbalances. The sample means of quoted spreads are very similar for 5-year (around 2 cents) and 10-years (around 3 cents) fixed income instruments, while longer-dated securities exhibit higher average spreads, ranging from 9 cents for Germany and Italy to 11 cents for France. In all cases, quoted spreads have lower serial correlation than order flow imbalances at all lags. As pointed out by D'Souza et al. (2007), this may arise from continuous quoting obligations, which may induce market makers to adjust quote quickly and, thus, to reduce serial correlations for quoted spreads.

[Table 2]

We remove possible seasonal patterns from our variables (due to deterministic timeseries variations or institutional features) using the two-step procedure proposed by Gallant et al. (1992), which is detailed in Appendix A.1. ${ }^{7}$ We check for the presence of a unit root in each seasonally adjusted series by means of the DF-GLS test (Elliott et al., 1996), allowing for an intercept as the deterministic component. As reported in Table 3, the unit-root null can be rejected at conventional significance levels in all cases. KPSS stationarity tests (Kwiatkowski et al., 1992) confirm this result.

[Table 3]

\section{3 - Dynamic interactions between quoted spreads and order imbalances}

Standard market microstructure theory posits that: 1) market-makers' survival depends on balanced inventories to be achieved through a continuous and strategic revision of quotes; 2)

algorithms, we are able to identify the initiator of the trade explicitly.

\footnotetext{
${ }^{7}$ Estimation details are not reported to save space, but are available on request.
} 
order flow imbalances contain relevant information for market-makers and influence their quoting activity and market liquidity; 3 ) by quoting wider spreads market-makers can hedge against the risks posed by informed traders (Kyle, 1985) and random shocks (Stoll, 1978). Accordingly, it is reasonable to expect past trading imbalances to affect the current width of spreads and vice versa.

In view of this, we choose a dynamic modelling approach as in D'Souza et al. (2007), controlling for changing market liquidity conditions as suggested by Pagano (1989), Eisfeldt (2004) and Brandt and Kavajecz (2004). Our econometric framework belongs to the class of Markov Switching VAR (MS-VAR, Krolzig, 1997) models, where a bivariate VAR process for oflw and $q s p r$ is modelled as time-invariant, conditional on an unobservable regime variable (see Appendix A.2).

After considerable experimentation, we selected a specification of the MS-VAR model that allows for regime shifts in the deterministic component, keeping constant the autoregressive part of the system and the covariance matrix of residuals across states:

$$
y_{t}-\mu\left(s_{t}\right)=\sum_{i=1}^{k} A_{i}\left[y_{t-i}-\mu\left(s_{t-i}\right)\right]+u_{t}, t=1, \ldots, T
$$

where $y_{t}$ is the vector collecting adjusted order flows and quoted spreads series, $\mu(s)$ is the vector of regime-dependent mean values, $s_{t}$ indicates the regime prevailing at time $t, A$ 's are matrices of autoregressive parameters, $k$ is the truncation order of the autoregression, $u_{t}$ is a vector of residuals and $T$ is the effective number of observations used in the estimation.

Adopting a "bottom up" procedure (Krolzig, 1997) to identify the models: a) the order of autoregression $k$ turns out to be one in six out of nine models and two in the remaining three cases (those relative to the Italian market); b) all models are subject to (at least) two different regimes and a three-regime model is appropriate in seven out of nine cases. ${ }^{8}$ The

\footnotetext{
${ }^{8}$ Diagnostics of the standardised residuals (available on request) provide strong evidence of no serial correlation.
} 
main properties of the estimated regimes are reported in Table 4. The average duration of each regime $j, d u r_{j}=1 /\left(1-p_{j j}\right)$, where $p_{j j}$ is the estimated probabilities of transition from regime $j$ to regime $j$, indicates that these are meaningful regime switching findings, with an average value of 5.24 (that is roughly three hours). Finally, the last numerical column reports the upper bound of the LR tests (Davies, 1977), which shows that the null hypothesis of linearity is rejected, giving support to a MS-VAR specification rather than a linear framework.

[Table 4]

Having identified (at most) three regimes, we define them as follows: 1) high liquidity if $\mu_{1}^{q s p r}\left(s_{t}\right)$ is lower than qspr whole-sample mean (state 1$)$; 2) low liquidity if $\mu_{3}^{\text {qspr }}\left(s_{t}\right)$ is higher than qspr whole-sample mean (state 3); 3) intermediate liquidity when $\mu_{1}^{q s p r}\left(s_{t}\right)<\mu_{2}^{q s p r}\left(s_{t}\right)<\mu_{3}^{q s p r}\left(s_{t}\right)($ state 2$)$.

Panel-A of Table 5 collects the estimated regime dependent mean values $\mu_{i}^{j}(i=1,2,3$; $j=$ oflw, qspr ). Panel-B presents the results from testing the symmetry between statistically positive and negative order flow imbalances and the equivalence of regime dependent mean values for quoted spreads. For each equation of the bivariate dynamic systems we also report the results of Granger-causality tests, with $p$-values in square brackets.

[Table 5]

The main findings can be summarised as follows. First, sell orders exceed buy orders when quoted spreads are low (except for FR0010288357 and IT0004026297) and the opposite is true when quoted spreads are high (except for DE0001141489 and IT0004026297). In the presence of heterogeneous private information (or heterogeneous interpretation of public explanatory power for the oflw and the qspr equations is 35 and 18 percent, respectively. 
information) trades occur on the basis of the market-makers' subjective valuations, which are updated monitoring the aggregate level of order flows (Brandt and Kavajecz, 2004). ${ }^{9}$ Inventory balance concerns induce market-makers to shift the spread upwards (downwards) when excess buy (sell)-orders occur. If excess buy (sell)-orders are interpreted as indicating that the quoted ask (bid) price is too low (high) with respect to the fundamental value, the upward (downward) shift is likely to be accompanied by a widening (narrowing) of the spread to better hedge against mis-pricing risk. This is also consistent with the presence of some dealers behaving like informed investors (Fleming and Remolona, 1999) with their trading based on superior inventory and order flow information (Huang et al., 2002) and reacting to the risk of inventory depletion (over-accumulation) in a situation where most of the market is on the demand (supply) side. According to this line of reasoning, our results reveal that when liquidity is in an intermediate state market participants give less importance to order flows, consistently with the findings in Chordia et al. (2002) for the aggregate US equity market.

Second, each regime is characterised by a statistically different level of liquidity as the null of mean equality across regimes for $q s p r$ is rejected in eight out of nine cases. ${ }^{10}$ Third, according to our classification, not all government bonds exhibit an intermediate liquidity regime: in the two-regime models (IT004026297 and IT0004019581), the states are associated to high and low liquidity conditions. ${ }^{11}$ Fourth, Granger-causality tests document bidirectional causality at the 5 percent significance level in six models. For two 5 -year bonds (FR0108354806 and IT004019581), causality runs from trading activity to quoted spreads, as predicted by standard paradigms of price formation. By contrast, there is evidence of reverse

\footnotetext{
${ }^{9}$ Thus, when an excess of buy-side orders occurs dealers with a lower (higher) subjective valuation tend to revise them upward (downward). The opposite holds when aggregate order flows are negative.

${ }^{10}$ In the remaining case (FR0010070060), however, the regime-dependent mean values are quite close to the estimates for the other two very-long term bonds in our sample.

${ }^{11}$ Notice that in the present framework liquidity regimes are endogenously determined by the maximum likelihood estimation procedure rather than ex-ante imposed as in Brandt and Kavajecz (2004).
} 
causality (from liquidity conditions to trading activity) only for FR0010070060.

\section{4 - Explaining shifts between liquidity regimes}

Because most of the data on the explanatory variables are not available at an intra-day frequency, we follow Clarida et al. (2006) and convert the intra-day smoothed probabilities from the estimated MS-VAR models into daily averages. For this purpose, we define a variable, $r$, which is equal to 2,1 and 0 when the average daily probability of being in the high, intermediate and low liquidity regime, respectively, is the highest among the probabilities associated with the various states.

\section{1 - Explanatory variables}

Building on Chordia et al. (2005), Hasbrouck and Seppi (2001), Eisfeldt (2004), Beber et al. (2009) and Korajczyk and Sadka (2008), we supplement the MTS dataset with information on interest rates ( repo), bond market returns and volatility ( $m k t r$ and $m k t v$, respectively), stock market volatility (stkv), macroeconomic announcements on inflation (infl), industrial production (indp), cyclical conditions of the real economy (unem $),{ }^{12}$ and an indicator of ECB liquidity provision ( malf ). Appendix B below provides details on each of these variables.

As further (time-invariant) regressors we introduce three market dummies (demm for Germany, frfm for France and $m t s m$ for Italy) to capture possible country-specific patterns and, following Dunne et al. (2007), three maturity dummies to control for maturity effects ( smty, Imty, vlmy for bonds with residual maturity of less than 6.5 years, higher than 6.6 and less than 13.5 years, and more than 13.5 years, respectively).

\footnotetext{
${ }^{12}$ Since most aggregate euro area data releases are published after the euro area countries have published their macro announcements, the informational value of euro area macro news is small (Andersson et al., 2006). Accordingly, in the empirical model presented in this Section we use country-specific macroeconomic releases.
} 


\section{2 - Commonality across government bonds in Europe}

We model the ordinal measure of the market liquidity stance, $r$, for each bond $i=1, \ldots, N$ over a number of trading days, indexed by $t=1, \ldots, T$, estimating a regression of the following form:

$$
r_{i t}=f\left(\text { repo }_{i t}, \text { mktr }_{i t}, \text { mktv }_{i t}, \text { stkv }_{i t}, \text { indp }_{i t}, \text { infl }_{i t}, \text { unem }_{i t}, \text { malf }_{i t}\right)
$$

Ordered Regression Models (ORMs) are presented in Table $6 .{ }^{13}$ Positive (negative) coefficients indicate a move toward a more (less) liquid state given an increase in the predictor. $^{14}$

\section{[Table 7]}

Estimation results from the pooled-ORM (A) show that liquidity in European bond markets increases when the bond market grows and decreases with increased inventory concerns due to soaring market volatility and to increased costs of financing inventories, in a way consistent with standard microstructure models. As for macroeconomic announcements, only unemployment news turns out to have a statistically significant and positive role in explaining switches across liquidity regimes. Finally, an increase in malf has a positive effect on the response variable, suggesting that policy interventions by monetary authorities may foster liquidity by making margin loan requirements less costly and by enhancing the ability of dealers to finance their positions (Garcia, 1989).

Controlling for unobserved time-invariant heterogeneity [Column (B)] gives qualitatively similar results, with a sizeable increase of the likelihood function. Random

\footnotetext{
${ }^{13}$ See Appendix A.3 for technical details. In order to control for possible endogeneity problems between the response variable and the explanatory variables we use in model (2) lagged values for all regressors but for macroeconomic announcements, because macro releases in general become public at the very beginning of trading hours.

14 The fixed thresholds (not reported in Table 6) in the pooled-ORM and in the RE-ORM specifications are statistically significant at the 5 percent level and at least one is different from 1, implying that the $J=2$ ordinal categories are not equally spaced.
} 
effects (RE-ORM) estimates, however, indicate that a number of important covariates play a very limited role. A possible explanation of these findings may be a specification error in the empirical framework due to the parallel regression assumption (PRA), according to which the effects of the predictors on the response variable are identical across categories. ${ }^{15} \mathrm{We}$ assess empirically such a conjecture by relaxing the PRA for those covariates that turned out to be weakly significant or statistically insignificant in the RE-ORM specification. Testing for PRA produces a LR test statistics (29.27) above the critical values of a $\chi^{2}$ distribution with 6 degrees of freedom at any significance level.

Column (C) presents the estimation results of the generalized RE-ORM model, where Equation 1 (Equation 2) refers to the probability that the response variable moves from low to medium (from medium to high) liquidity conditions. While the impact of $m k t r$ and $m k t v$ remains unchanged with respect to previous specifications, the split reveals some interesting asymmetric effects for the remaining predictors. Refinancing costs, stock market volatility and industrial production news have a significant negative impact on liquidity in Equation 1 only. In Equation 2, instead, refinancing costs have no significant impact, while the impact of stock market volatility, unemployment news and ECB liquidity support is positive.

We use this model to measure how the probabilities of the three liquidity states change in response to different market and macroeconomic conditions. This is done by re-calculating $\operatorname{Pr}\left(r_{i t}=0\right), \operatorname{Pr}\left(r_{i t}=1\right)$ and $\operatorname{Pr}\left(r_{i t}=2\right)$, moving one regressor at the time from its sample minimum to its maximum while keeping the other predictors constant at their sample averages. This exercise is performed only for time-varying, statistically significant regressors. In each graph of Figure 1, the vertical axis indicates the probability associated to a specific state of liquidity. The horizontal axis reports these probabilities, computed at the minimum as

\footnotetext{
15 It may be the case, indeed it is likely, that covariates have distinctive effects within different categories, implying that the analysis based on the PRA may reveal no net effect.
} 
well as at the first quartile, at the median, at the third quartile and at the maximum values of the distribution of each predictor, ceteris paribus.

[Figure 1]

When refinancing costs rise, the probability of low liquidity states increases whilst that of the intermediate state decreases. At very high levels of repo there is a higher probability of extreme liquidity conditions and, thus, of inventory concerns. Moving from very low to very high levels of mktr induces a monotonic decline in the probability of low liquidity along with an increase in the probability of high liquidity conditions, in a way consistent with momentum strategies. Higher bond market volatility is associated with lower liquidity as $\operatorname{Pr}\left(r_{i t}=0\right)$ rises and $\operatorname{Pr}\left(r_{i t}=2\right)$ falls. As stock market volatility increases the probability associated with the intermediate liquidity state disappears, with trade-order imbalances prevailing. The ECB's marginal lending provides an effective hedge against liquidity evaporation only in extreme cases, i.e. when malf is above a certain threshold (the third quartile of its sample distribution). Finally, the relationship between macro announcements and the response variable is consistent with bond market liquidity being counter-cyclical. In particular extremely favourable industrial production and unemployment news lead to a significant increase in $\operatorname{Pr}\left(r_{i t}=0\right)$. Given the pro-cyclicality of stock market liquidity (see Eisfeldt, 2004), our results suggest that bond and stock market liquidity should be seen as substitutes rather than as complements over the business cycle.

\section{5 - Conclusions}

This paper analyses transaction-based data for Treasury bonds with maturities of 5, 10 and 32 years for the three largest European markets, namely Italy, France and Germany, with the aim of shedding light on the secondary market for Treasury securities in Europe.

The MS-VAR estimation results suggest that in abnormal (i.e. very high or very low) 
market liquidity conditions dealers pay attention to the information revealed by order flows; less so when liquidity is in an intermediate state. Furthermore, the causality nexus between quoted spreads and trading imbalances is a complex one: for a vast majority of bonds, we find bi-directional feedback effects between market characteristics. Ordered probit estimates for longitudinal data indicate that extreme liquidity conditions are likely to occur when refinancing costs are low, according to standard portfolio rebalancing arguments. By exacerbating inventory risk, bond market volatility has a detrimental effect on aggregate liquidity, while bond market returns induce changes in the composition of portfolios. Furthermore, we find that liquidity states evolve counter-cyclically with respect to the sentiment among analysts about the business climate. Higher stock market volatility increases the probability of extreme liquidity conditions and trade-order imbalances. Finally, bond market liquidity reacts positively to an increase in the volume of the marginal lending facility only if the size of the liquidity provision offered by the ECB is above a certain threshold.

It is noteworthy that our sample ends a few weeks before the outbreak in 2007 of the current financial turmoil. Although the stochastic properties of financial series during periods of stress are likely to differ substantially from those in normal times, we interpret our findings as indicating that European monetary authorities can provide effective insurance against liquidity evaporation in the euro-denominated government bond market only to the extent that they are willing to increase the monetary base sharply through standard and ad hoc lending facilities. Further work based on an updated sample could shed light on the most recent effects of the financial turmoil on the European Treasury securities market. Another possible extension could also model shifts across liquidity regimes for individual bonds. In this respect, endogenising the MS-VAR estimated transition probabilities (making them dependent on market characteristics as well as on institutional factors) could be useful to increase market participants' knowledge of the market microstructure properties of the MTS 
platform. Finally, depth and price dynamics could be introduced as dependent variables in the MS-VAR estimation in order to test hypotheses based on the limit order market literature (see Rosu, 2009 and Foucault et al., 2005) and to assess whether price dynamics react differently to liquidity in different regimes as in Brandt and Kavajecz (2004). These issues are left for future research. 


\section{Appendix A. Econometric tools}

\section{A.1 - Seasonal adjustment procedure}

The procedure proposed by Gallant et al. (1992) consists of two steps. The first stage is to regress raw measures of trading imbalances, oflw $w_{t}$, and quoted spreads, $q s p r_{t}^{*}$, on a series of $j$ adjustment variables, $\gamma_{i}, \quad i=1, \ldots, j: \quad z_{t}^{*}=\sum_{i=1}^{j} d_{i} \gamma_{i}+\varepsilon_{t} \quad$ (mean equation), where $z_{t}^{*}=o f l w_{t}^{*}, q s p r_{t}^{*}$, alternatively, and $t$ indexes time. In order to remove heteroscedasticity, the residuals $\varepsilon_{t}$ are used in the following regression $\ln \left(\varepsilon_{t}^{2}\right)=\sum_{i=1}^{j} f_{i} \gamma_{i}+\xi_{t}$ (variance equation). The adjusted series, $z_{t}$, are then calculated as:

$$
z_{t}=\alpha+\left[\beta \hat{\varepsilon}_{t} / \exp \left(\sum_{i=1}^{j} f_{i} \gamma_{i} / 2\right)\right]
$$

where $\hat{\varepsilon}_{t}$ are the estimated residuals and the parameters $\alpha$ and $\beta$ are chosen so that the sample means and variances of the adjusted and the unadjusted series are the same. ${ }^{16}$ The following adjustment variables are used: i) 11 monthly dummies, one for each month from February to December; ii) 4 daily dummies, one for each day from Monday to Thursday, iii) 17 half-hourly dummies, one for each hour from 9:00 (CET) and 17:30 (CET), iv) 3 dummies, taking value 1 , if the bond has the benchmark or the first off-the-run or the second off-the-run status, alternatively, and 0 , otherwise; v) a dummy taking value 1 , if trades take place on the domestic MTS platform, and 0, otherwise, as in Cheung et al. (2005), vi) a dummy taking value 1 , if trades are initiated by a market maker, and 0 , otherwise.

\section{A.2 - Modelling quoted spreads and trading imbalance dynamics}

For expositional purposes, we outline below the MS-VAR framework for the case of regime shifts in the mean alone, although shifts may be allowed for elsewhere. Adopting the same

\footnotetext{
${ }^{16}$ Results based on the seasonally adjusted series are available on request.
} 
notation as above, the $\operatorname{MSM}(m)-\operatorname{VAR}(p)$ model, following Krolzig (1997), can be written as:

$$
\left[\begin{array}{l}
q s p r_{t} \\
o f l w_{t}
\end{array}\right]-\left[\begin{array}{c}
\mu^{q s p r}\left(s_{t}\right) \\
\mu^{o f l w}\left(s_{t}\right)
\end{array}\right]=\sum_{i=1}^{k}\left[\begin{array}{ll}
a_{11, i} & a_{12, i} \\
a_{21, i} & a_{22, i}
\end{array}\right]\left(\left[\begin{array}{l}
q s p r_{t-i} \\
o f l w_{t-i}
\end{array}\right]-\left[\begin{array}{c}
\mu^{q s p r}\left(s_{t-i}\right) \\
\mu^{o f l w}\left(s_{t-i}\right)
\end{array}\right]\right)+\left[\begin{array}{l}
u_{t}^{q s p r} \\
u_{t}^{o f l w}
\end{array}\right]
$$

The regime $s_{t}$ is assumed to be governed by a discrete time irreducible ergodic $m$-state stochastic Markov process with transition probabilities $p_{i j}=\operatorname{Pr}\left(s_{t+1}=j \mid s_{t}=i\right), \sum_{j=1}^{m} p_{i j}=1$, $i, j \in\{1, \ldots, m\}$, collected in the transition matrix $P=\left\{p_{i j}\right\}_{m \times m}$. Following a regime shift in the mean $\mu\left(s_{t}\right)$ of model (A1), the observed time series jumps immediately to its new level. Such a feature appears to be adequate for our purposes since we are dealing with financial variables and therefore sudden jumps across states are more plausible than gradual swings.

In order to find detect an adequate characterisation of an $m$-regime $k$-th order VAR, we apply the "bottom-up" procedure (Krolzig, 1997). This approach allows to select both the number of regimes and the autoregressive order using the approximation provided by its VARMA representation (Poskitt and Chung, 1996), starting with a simple but statistically reliable MS-VAR model by restricting the effects of regime shifts on a limited number of parameters and checking the model against alternatives.

Parameter estimation is carried out through the implementation of the expectationmaximisation algorithm for maximum likelihood estimation (Dempster et al., 1977). To test for a dynamic link between quoted spreads and trading imbalances, Granger causality tests are conducted. For instance, to test for Granger causality from order flow imbalances to quoted spreads, the null hypothesis of non-causality is:

$$
H_{0}: a_{12, i}=0, \forall i=1, \ldots, k
$$

To test the null, we impose the restrictions in (A2) on the values of the autoregressive parameters so as to obtain the log likelihood value of the constrained MS-VAR model $\left(L_{c o n}\right)$. 
By comparing $L_{c o n}$ to the value of the log likelihood of the unrestricted model $\left(L_{u n r}\right)$ from (A1), a standard $\chi^{2}$-distributed (with $k$ degrees of freedom) likelihood ratio $(L R)$ test statistic is calculated using the formula $L R=2\left(L_{u n r}-L_{c o n}\right)$. Furthermore, in terms of inference, we follow Nelson et al. (2001) who conclude that unit root tests remain robust in detecting stationarity in Markov switching regressions.

\section{A.3 - Analysing the determinants of market liquidity states}

Considering pooling data, the basic notion underlying ORMs is the existence of a latent (or unobserved) continuous variable, $r_{i t}^{*}$, ranging from $-\infty$ to $+\infty$, which is related to a set of explanatory variables through the standard linear relationship:

$$
r_{i t}^{*}=\beta^{\prime} x_{i t}+\gamma^{\prime} z_{i}+u_{i t}
$$

where $x_{i t}$ is a vector of time-varying regressors, $z_{i}$ is a vector of time-invariant covariates, $\beta$ and $\gamma$ are the associated parameter vectors and $u_{i t}$ is a random error term.

Although $r_{i t}^{*}$ is unobserved, it is related to the integer index $r_{i t}$ through the relationship:

$$
r_{i t}=0 \text { iff } r_{i t}^{*}<\lambda_{1}, r_{i t}=j \text { iff } \lambda_{j-1}<r_{i t}^{*}<\lambda_{j}, j=2, \ldots, J-1, r_{i t}=J \text { iff } r_{i t}^{*}>J-1 \text {, }
$$

where $\lambda_{j}$ are the unobserved thresholds defining the boundaries between different levels of $r_{i t}$. Given the relationship between $r_{i t}$ and $r_{i t}^{*}$, we can express the conditional cell probabilities (that is, the probability of observing an individual as having a $j$ value of $r_{i t}$ ) as:

$$
\operatorname{Pr}\left(r_{i t}=j \mid x_{i t}, z_{i}\right)=F\left(\lambda_{j}-\beta^{\prime} x_{i t}-\gamma^{\prime} z_{i}\right)-F\left(\lambda_{j-1}-\beta^{\prime} x_{i t}-\gamma^{\prime} z_{i}\right)
$$

where $F($.$) indicates the cumulative distribution function, with \lambda_{j}>\lambda_{j-1}, \forall j \in 1, \ldots, J$. The set of equations (A4) can be used to compute the cumulative probabilites:

$$
\operatorname{Pr}\left(r_{i t} \leq j \mid x_{i t}, z_{i}\right)=F\left(\lambda_{j}-\beta^{\prime} x_{i t}-\gamma^{\prime} z_{i}\right)
$$

Assuming a standard normal distribution yields the ordered probit model. 
In order to fully capture the effect of individual heterogeneity, the random effects approach (RE-ORM) assumes that both time-invariant, $v_{i}$, and time-varying, $\varepsilon_{i t}$, unobserved factors may contribute to determine liquidity conditions. If we express the random error term as $u_{i t}=v_{i}+\varepsilon_{i t}$, model (A3) can be written as $r_{i t}^{*}=\beta^{\prime} x_{i t}+\gamma^{\prime} z_{i}+v_{i}+\varepsilon_{i t}$, where both error components are normally distributed and orthogonal to the set of predictors. Since the underlying variance of the composite error, $\sigma_{u}^{2}=\sigma_{v}^{2}+\sigma_{\varepsilon}^{2}$, is not identified, we normalise $\sigma_{\varepsilon}^{2}=1$, so that $\rho_{u_{i t}, u_{i s}}=\sigma_{v}^{2}\left(\sigma_{v}^{2}+\sigma_{\varepsilon}^{2}\right)^{-1}=\sigma_{v}^{2}\left(\sigma_{v}^{2}+1\right)^{-1}$, and, thus, $\sigma_{v}=[\rho /(1-\rho)]^{1 / 2}$.

Notice that both the standard pooled-ORM and the RE-ORM frameworks rely on the critical parallel regression assumption (PRA), according to which the effects of the covariates on the dependent variable are identical across the $J$ categories of the response variable. In a generalised RE-ORM framework (Boes and Winkelmann, 2006), time-invariant individual effects may vary across categories, with threshold parameters dependent on the predictors.

The conditional probability model (A4) for the case of a generalised RE-ORM changes into the following one:

$$
\operatorname{Pr}\left(r_{i t}=j \mid x_{i t}, z_{i} ; \beta_{j}, \gamma_{j}\right)=\Phi\left(-v_{i j}-\beta_{j}^{\prime} x_{i t}-\gamma_{j}^{\prime} z_{i}\right)-\Phi\left(-v_{i j-1}-\beta_{j-1}^{\prime} x_{i t}-\gamma_{j-1}^{\prime} z_{i}\right)
$$

which makes it possible to write down the corresponding cumulative model as:

$$
\operatorname{Pr}\left(r_{i t} \leq j \mid x_{i t}, z_{i} ; \beta_{j}, \gamma_{j}\right)=\Phi\left(-v_{i j}-\beta_{j}^{\prime} x_{i t}-\gamma_{j}^{\prime} z_{i}\right)
$$

where $\Phi($.$) denotes the normal cumulative distribution function.$

Under the hypothesis of equal slope parameters for both time-varying and timeinvariant regressors, the standard RE-ORM is nested into the generalised threshold RE-ORM. The (implicit) restrictions embedded in the former can be tested against the latter by performing a $\chi^{2}$-distributed LR test.

The computation of the marginal probability effects (mpe), that is the shift of the predicted discrete ordered distribution of the outcome variable as one (or more) of the 
predictors' changes, in the case of a generalised RE-ORM is performed under the hypothesis of normally distributed $v_{i j}$ 's, so that the $\beta$ 's and the $\gamma$ 's parameters are rescaled in the population-averaged coefficient vectors $\tilde{\beta}=\beta /\left(1+\sigma_{v}^{2}\right)^{1 / 2}$ and $\tilde{\gamma}=\gamma /\left(1+\sigma_{v}^{2}\right)^{1 / 2}$, respectively (Boes and Winkelmann (2006). Accordingly, the mpe exerted by the $k$-th element in $x_{i t}$, $x_{i t}^{(k)}$, on the $j$-th ordered category of the response variable can be expressed as:

$$
\begin{aligned}
m p e_{j}^{k} & =\left[\left(\partial \operatorname{Pr}\left(r_{i t}=j \mid x_{i t} ; \tilde{\beta}\right) / \partial x_{i t}^{(k)}\right)\right]= \\
& =\phi\left(-v_{i j-1}-\beta_{j-1}^{\prime} x_{i t}-\gamma_{j-1}^{\prime} z_{i}\right) \tilde{\beta}_{j-1}^{(k)}-\phi\left(-v_{i j}-\beta_{j}^{\prime} x_{i t}-\gamma_{j}^{\prime} z_{i}\right) \tilde{\beta}_{j}^{(k)}
\end{aligned}
$$

where $\beta^{(k)}$ indicates the $k$-th element in vector $\beta$ and $\phi(z) \equiv d \Phi(z) / d z$.

Simulated probabilities are obtained by using the cumulative model, by moving a predictor from its minimum to maximum. Since simulated probabilities depend on the individual elements of $x_{i t}$ and $z_{i}$, we evaluate them at the sample average of the predictors. 


\section{Appendix B. Construction of time-varying drivers of liquidity states}

In order to control for possible trend patterns in the covariates over the sample span, we define relative quantities with respect to European averages values. All variables are constructed by using daily data.

repo is the difference between bond specific spot next repo rates and the Euro short term repo (middle rate) by the ECB. Repo rates are from MTS database and Datastream. mktr is the difference between HP-filtered log-prices of the country-specific EuroMTS index and of the European aggregate EuroMTS index (with the same maturity of the bond). mktv is the absolute value of the difference between the first differences of the log-prices of the country-specific EuroMTS index and of the European aggregate EuroMTS index (with the same maturity of the bond). Data for mktr and mktv are extracted from the EuroMTS website (http://www.euromtsindex.com/). stkv is the absolute value of the difference between the first differences of the log-prices of the country-specific stock index and of the DJ Euro 600 index. The data source is Datastream.

For each announcement, we construct the standardised scheduled news, given by the difference between the value announced and the median of survey expectation of announcement divided by the sample standard deviation of that difference. We set the standardised scheduled news equal to zero on days without macroeconomic announcements. Country-specific announcement data as well as the survey expectation of the announcements on year-on-year changes of inflation (infl), industrial production (indp) and unemployment (unem) are taken from Bloomberg. Finally, malf is the standardised value (i.e. the difference between actual values and the sample average divided by the sample standard deviation) of the amount (in EUR millions) of volumes for marginal lending facility published on the ECB website (http://www.ecb.eu/stats/monetary/res/html/index.en.html\#data). 


\section{References}

1. Beber A., M. W. Brandt and K. A. Kavajecz (2009), Flight-to-Quality or Flight-to-Liquidity? Evidence From the Euro-Area Bond Market, Review of Financial Studies, 22, pp. 925-957.

2. Boes, S. and R. Winkelmann (2006), The Effect of Income on Positive and Negative Subjective WellBeing, mimeo, University of Zurich.

3. Brandt M. W. and K. A. Kavajecz (2004), Price Discovery in the U.S. Treasury Market: The Impact of Order flow and Liquidity on the Yield Curve, Journal of Finance, 59, pp. 2623-2654.

4. Caporale G. M. and A. Girardi (2010), Price Formation on the EuroMTS Platform, Applied Economics Letters, forthcoming.

5. Cheung C., F. de Jong and B. Rindi (2005), Trading European Sovereign Bonds: The Microstructure of the MTS Trading Platforms, ECB Working Paper, 432.

6. Chordia T., R. Roll and A. Subrahmanyam (2001), Market Liquidity and Trading Activity, Journal of Finance, 56, pp. 501-530.

7. Chordia T., R. Roll and A. Subrahmanyam (2002), Order Imbalance, Liquidity and Market Returns, Journal of Financial Economics, 65, pp. 111-130.

8. Chordia T., A. Sarkar and A. Subrahmanyam (2005), An Empirical Analysis of Stock and Bond Market Liquidity, Review of Financial Studies, 18, p. 85-129.

9. Clarida R. H., L. Sarno, M. P. Taylor and G. Valente (2006), The Role of Asymmetries and Regime Shifts in the Term Structure of Interest Rates, Journal of Business, 79, pp. 1193-1224.

10. Coluzzi C. and S. Ginebri (2008), Order Dynamics in the Italian Treasury Security Wholesale Secondary Market, University of Molise, Economics \& Statistics Discussion Paper, 50/08.

11. Davies R. (1977), Hypothesis Testing when a Nuisance Parameter is Present only under the Alternative, Biometrika, 64, pp. 247-254.

12. Dempster A. P., N. M. Laird and D. B.Rubin (1977), Maximum Likelihood Estimation from Incomplete Data via the EM Algorithm, Journal of the Royal Statistical Society, 39, Series B, pp. 1-38.

13. D’Souza C., I. Lo and S. Sapp (2007), Price Formation and Liquidity Provision in Short-Term Fixed Income Markets, Bank of Canada Working Paper, 2007-27.

14. Dunne P. G., H. Hau and M. J. Moore (2008), A Tale of Two Platforms: Dealer Intermediation in The 
European Sovereign Bond Market, CEPR Discussion Papers, 6969.

15. Dunne P. G., M. J. Moore and R. Portes (2007), Benchmark Status in Fixed-Income Asset Markets, Journal of Business Finance and Accounting, 34, pp. 1615-1634.

16. Eisfeldt A. (2004), Endogenous Liquidity in Asset Markets, Journal of Finance, 59, pp. 1-30.

17. Elliott G., T. Rothenberg and J. H. Stock (1996), Efficient Tests for an Autoregressive Unit Root, Econometrica, 64, pp. 813-836.

18. Fleming M. and E. Remolona (1999), Price Formation and Liquidity in the U.S. Treasury Market: The Response to Public Information, Journal of Finance, 54, pp. 1901-1915.

19. Foucault T., O. Kadan and E. Kandel (2005), Limit Order Book as a Market for Liquidity, Review of Financial Studies, 18, pp. 1171-1217.

20. Gallant A., P. Rossi and G. Tauchen (1992), Stock Prices and Volume, Review of Financial Studies, 5, pp. 199-242.

21. Garcia G. (1989), The Lender of Last Resort in the Wake of the Crash, American Economic Review, 79, pp. 151-155.

22. Goldreich D., B. Hanke, and P. Nath (2005), The Price of Future Liquidity: Time-Varying Liquidity in the US Treasury Market, Review of Finance, 9, pp. 1-32.

23. Hasbrouck J. and D. Seppi (2001), Common Factors in Prices, Order Flows, and Liquidity, Journal of Financial Economics, 59, pp. 383-411.

24. Huang R., J. Cai and X. Wang (2002), Inventory Risk-sharing and Public Information-based Trading in the Treasury Note Interdealer Broker Market, Journal of Financial Intermediation, 11, pp. 269-296.

25. Johnson T. C. (2008), Volume, Liquidity, and Liquidity Risk, Journal of Financial Economics, 87, pp. 388417.

26. Korajczyk R. A. and R. Sadka (2008), Pricing the Commonality across Alternative Measures of Liquidity, Journal of Financial Economics, 87, pp. 45-72.

27. Krolzig H. M. (1997), Markov-Switching Vector Autoregressions. Modelling, Statistical Inference and Application to Business Cycle Analysis, Springer Verlag, Berlin.

28. Kyle A. (1985), Continuous Auctions and Insider Trading, Econometrica, 53, pp. 131-1335.

29. Kwiatkowski D., P. C. B. Phillips, P. Schmidt and Y. Shin (1992), Testing the Null Hypothesis of 
Stationary against the Alternative of a Unit Root, Journal of Econometrics, 54, pp. 159-178.

30. Menkveld A. J., Y. C. Cheung and F. de Jong (2004), Euro Area Sovereign Yield Dynamics: The Role of Order Imbalance, ECB Working Paper, 385.

31. Nelson C. R., J. Piger and E. Zivot (2001), Markov Regime Switching and Unit-Root Tests, Journal of Business and Economic Statistics, 19, pp. 404-415.

32. Pagano M. (1989), Trading Volume and Asset Liquidity, Quarterly Journal of Economics, 104, pp. 255274.

33. Pasquariello P. and C. Vega (2009), The On-The-Run Liquidity Phenomenon, Journal of Financial Economics, 92, pp. 1-24.

34. Poskitt D. S. and S. H. Chung (1996), Markov-chain Models, Time Series Analysis and Extreme Value Theory, Advances in Applied Probability, 28, pp. 405-425.

35. Rosu I. (2009), A Dynamic Model of the Limit Order Book, Review of Financial Studies, 22, pp. 46014641.

36. Scalia A. and V. Vacca (1999), Does Market Transparency Matter? A Case Study, BIS Papers, 2, p. 113144 (with comments)

37. Schwert G. W. (1989), Tests for Unit Roots: A Monte Carlo Investigation, Journal of Business and Economic Statistics, 7, pp. 147-159.

38. Stoll H. (1978), The Pricing of Security Dealer Services: An Empirical Study of NASDAQ Stocks, Journal of Finance, 33, pp. 1153-1172.

39. Upper C. and T. Werner (2002), How Resilient Are Financial Markets to Stress? Bund Futures and Bonds during the 1998 Turbulence, BIS Papers, 12, pp. 110-123. 


\section{Tables}

Table 1 - Bond codes

\begin{tabular}{ccccccc}
\hline Market code & Bond code & Issue date & Maturity date & Maturity (years) & $\begin{array}{c}\text { Trades on domestic } \\
\text { MTS (\%) }\end{array}$ & $\begin{array}{c}\text { Trades by market } \\
\text { makers }(\%)\end{array}$ \\
\hline \multirow{2}{*}{ Germany } & DE0001141489 & $3 / 22 / 2006$ & $4 / 8 / 2011$ & 5.05 & 84.31 & 98.04 \\
& DE0001135291 & $11 / 23 / 2005$ & $1 / 4 / 2016$ & 10.12 & 56.31 & 89.08 \\
& DE0001135275 & $1 / 4 / 2005$ & $1 / 4 / 2037$ & 32.02 & 73.81 & 97.81 \\
\hline \multirow{2}{*}{ France } & FR0108354806 & $1 / 19 / 2006$ & $1 / 12 / 2011$ & 4.98 & 79.49 & 99.36 \\
& FR0010288357 & $2 / 2 / 2006$ & $4 / 25 / 2016$ & 10.23 & 47.21 & 98.83 \\
\hline \multirow{2}{*}{ Italy } & FR0010070060 & $4 / 25 / 2003$ & $4 / 25 / 2035$ & 32.02 & 81.64 & 100.00 \\
\hline & IT0004026297 & $3 / 13 / 2006$ & $3 / 15 / 2011$ & 5.01 & 91.59 & 99.70 \\
\hline
\end{tabular}

Note. For each market, the first, the second, and the third code refers to the 5,10 and 30-year bond, respectively. 
Table 2 - Summary statistics for liquidity and trading activity measures

\begin{tabular}{ccccccccccccc}
\hline & & \multicolumn{4}{c}{ Quoted Spreads } & \multicolumn{5}{c}{ Trade Imbalances } \\
Bond code & $x_{M}$ & $x_{M e}$ & $x_{S D}$ & $\rho_{1}$ & $\rho_{2}$ & $\rho_{3}$ & $x_{M}$ & $x_{M e}$ & $x_{S D}$ & $\rho_{1}$ & $\rho_{2}$ & $\rho_{3}$ \\
\hline DE0001141489 & 0.025 & 0.025 & 0.007 & $\mathbf{0 . 2 6 4}$ & $\mathbf{0 . 1 8 0}$ & 0.136 & -5.944 & -7.500 & 21.650 & $\mathbf{0 . 7 1 0}$ & $\mathbf{0 . 5 1 3}$ & $\mathbf{0 . 3 9 6}$ \\
DE0001135291 & 0.032 & 0.031 & 0.011 & $\mathbf{0 . 4 1 2}$ & $\mathbf{0 . 2 4 1}$ & $\mathbf{0 . 1 8 1}$ & -4.824 & -2.500 & 25.089 & $\mathbf{0 . 8 1 4}$ & $\mathbf{0 . 6 6 9}$ & $\mathbf{0 . 5 3 9}$ \\
DE0001135275 & 0.092 & 0.087 & 0.033 & $\mathbf{0 . 6 1 0}$ & $\mathbf{0 . 4 1 4}$ & $\mathbf{0 . 3 1 1}$ & -0.069 & 0.000 & 16.990 & $\mathbf{0 . 8 5 0}$ & $\mathbf{0 . 7 1 3}$ & $\mathbf{0 . 5 9 0}$ \\
FR0108354806 & 0.027 & 0.028 & 0.007 & $\mathbf{0 . 3 8 4}$ & $\mathbf{0 . 1 8 4}$ & 0.054 & 2.679 & -10.000 & 32.531 & $\mathbf{0 . 8 9 0}$ & $\mathbf{0 . 7 8 6}$ & $\mathbf{0 . 6 9 4}$ \\
FR0010288357 & 0.035 & 0.032 & 0.019 & $\mathbf{0 . 5 9 4}$ & $\mathbf{0 . 2 8 8}$ & 0.038 & -11.050 & -5.000 & 39.302 & $\mathbf{0 . 8 8 6}$ & $\mathbf{0 . 7 8 0}$ & $\mathbf{0 . 6 8 3}$ \\
FR0010070060 & 0.112 & 0.113 & 0.032 & $\mathbf{0 . 1 7 9}$ & 0.136 & 0.069 & 3.551 & 5.000 & 12.937 & $\mathbf{0 . 8 3 7}$ & $\mathbf{0 . 7 1 8}$ & $\mathbf{0 . 6 2 0}$ \\
IT0004026297 & 0.019 & 0.020 & 0.006 & $\mathbf{0 . 5 7 2}$ & $\mathbf{0 . 3 9 4}$ & $\mathbf{0 . 2 6 3}$ & -13.059 & -5.000 & 63.370 & $\mathbf{0 . 9 5 5}$ & $\mathbf{0 . 9 1 3}$ & $\mathbf{0 . 8 7 5}$ \\
IT0004019581 & 0.026 & 0.025 & 0.008 & $\mathbf{0 . 7 9 2}$ & $\mathbf{0 . 6 5 9}$ & $\mathbf{0 . 5 5 4}$ & 3.850 & 5.000 & 80.238 & $\mathbf{0 . 9 5 7}$ & $\mathbf{0 . 9 1 4}$ & $\mathbf{0 . 8 7 1}$ \\
IT0003934657 & 0.093 & 0.093 & 0.031 & $\mathbf{0 . 6 6 4}$ & $\mathbf{0 . 5 1 7}$ & $\mathbf{0 . 4 2 6}$ & 4.812 & 2.500 & 38.994 & $\mathbf{0 . 9 5 8}$ & $\mathbf{0 . 9 1 5}$ & $\mathbf{0 . 8 7 3}$ \\
\hline
\end{tabular}

Note. For each bond, we report the mean $\left(x_{M}\right)$, the median $\left(x_{M e}\right)$ and the standard deviation $\left(x_{S D}\right)$ of quoted spreads and order flows along with their serial correlations up to the third lag $\left(\rho_{i} i, i=1,2,3\right)$. Values in bold indicate statistically significant autocorrelation coefficients at the 5 percent level. Market codes for German, French and Italian bonds are DE..., FR.. and IT..., respectively. For each market, the first, the second, and the third code refers to the 5,10 and 30-year bond, respectively. 
Table 3 - Unit root test results

\begin{tabular}{ccccccc}
\hline & \multicolumn{2}{c}{ Quoted Spreads } & & \multicolumn{2}{c}{ Trade Imbalances } \\
Bond code & Lags & DF-GLS & KPSS & Lags & DF-GLS & KPSS \\
\hline DE0001141489 & 1 & -6.537 & 0.120 & 1 & -7.608 & 0.100 \\
DE0001135291 & 2 & -2.733 & 0.152 & 1 & -9.680 & 0.161 \\
DE0001135275 & 2 & -14.655 & 0.158 & 1 & -13.553 & 0.458 \\
FR0108354806 & 1 & -2.432 & 0.050 & 1 & -5.045 & 0.120 \\
FR0010288357 & 3 & -3.634 & 0.169 & 1 & -8.058 & 0.251 \\
FR0010070060 & 2 & -3.343 & 0.070 & 1 & -5.866 & 0.179 \\
IT0004026297 & 1 & -24.054 & 0.121 & 2 & -9.099 & 0.291 \\
IT0004019581 & 3 & -26.817 & 0.080 & 1 & -19.089 & 0.340 \\
IT0003934657 & 3 & -17.117 & 0.052 & 1 & -10.641 & 0.632 \\
\hline
\end{tabular}

Note. Critical values at the 10, 5 and 1 percent significance levels for the DF-GLS test (Elliot et al., 1996) for the unit root null, in the case of a constant as the deterministic component of the regression, are -2.62, -2.03 and 1.73 , respectively. The order of autoregression ("Lags") is chosen according to the modified Akaike Information Criterion. Critical values at the 10,5 and 1 percent significance levels for the KPSS test (Kwiatkowski et al., 1992) for the null of stationarity, in the case of a constant as the deterministic component of the regression, are $0.35,0.46$ and 0.74 , respectively. The order of autoregression ("Lags") is chosen according to the rule provided by Schwert (1989). Market codes for German, French and Italian bonds are DE..., FR.. and IT..., respectively. For each market, the first, the second, and the third code refers to the 5,10 and 30-year bond, respectively. 
Table 4-Properties of Markov switching regimes

\begin{tabular}{|c|c|c|c|c|c|c|c|c|}
\hline & Lags & $p_{11}$ & $p_{22}$ & $p_{33}$ & $d u r_{1}$ & $d u r_{2}$ & $d u r_{3}$ & Davies \\
\hline DE0001141489 & 1 & 0.185 & 0.400 & 0.841 & 1.227 & 1.667 & 6.281 & {$[0.000]$} \\
\hline DE0001135291 & 1 & 0.413 & 0.782 & 0.599 & 1.703 & 4.585 & 2.491 & {$[0.000]$} \\
\hline DE0001135275 & 1 & 0.792 & 0.832 & 0.691 & 4.803 & 5.942 & 3.234 & {$[0.000]$} \\
\hline FR0108354806 & 1 & 0.804 & 0.882 & 0.475 & 5.112 & 8.460 & 1.905 & {$[0.003]$} \\
\hline FR0010288357 & 1 & 0.662 & 0.731 & 0.589 & 2.962 & 3.713 & 2.435 & {$[0.000]$} \\
\hline FR0010070060 & 1 & 0.525 & 0.735 & 0.786 & 2.103 & 3.771 & 4.675 & {$[0.010]$} \\
\hline IT0004026297 & 2 & 0.929 & . & 0.883 & 13.986 & . & 8.525 & {$[0.000]$} \\
\hline IT0004019581 & 2 & 0.927 & . & 0.900 & 13.624 & . & 9.950 & {$[0.000]$} \\
\hline IT0003934657 & 2 & 0.837 & 0.853 & 0.797 & 6.139 & 6.803 & 4.931 & {$[0.000]$} \\
\hline
\end{tabular}

Note. The order of autoregression is reported in the column "Lags". $p_{j j}$ 's $(j=1,2,3)$ are the estimated probabilities of transition from regime $j$ to regime $j$. The average duration of each regime $j, d u r_{j}$, is calculated as $d u r_{j}=1 /\left(1-p_{j j}\right)$. Davies is the upper bound of the LR tests for the null of a linear VAR. $p$-values are in squared brackets. Market codes for German, French and Italian bonds are DE..., FR.. and IT..., respectively. For each market, the first, the second, and the third code refers to the 5, 10 and 30-year bond, respectively. 
Table 5 - MS-VAR estimation results

\begin{tabular}{|c|c|c|c|c|c|c|}
\hline \multirow[b]{2}{*}{ Panel A } & \multicolumn{3}{|c|}{ Equation: Quoted Spreads } & \multicolumn{3}{|c|}{ Equation: Order Flow Imbalances } \\
\hline & $\mu_{1}$ & $\mu_{2}$ & $\mu_{3}$ & $\mu_{1}$ & $\mu_{2}$ & $\mu_{3}$ \\
\hline DE0001141489 & $\begin{array}{c}\mathbf{0 . 0 1 5} \\
(0.004)\end{array}$ & $\begin{array}{c}\mathbf{0 . 0 2 5} \\
(0.004)\end{array}$ & $\begin{array}{c}\mathbf{0 . 0 2 6} \\
(0.002)\end{array}$ & $\begin{array}{c}6.811 \\
(4.478)\end{array}$ & $\begin{array}{l}\mathbf{7 8 . 8 7 5} \\
(5.763)\end{array}$ & $\begin{array}{l}\mathbf{- 1 1 . 4 1 8} \\
(2.067)\end{array}$ \\
\hline DE0001135291 & $\begin{array}{c}\mathbf{0 . 0 1 5} \\
(0.003)\end{array}$ & $\begin{array}{c}\mathbf{0 . 0 3 5} \\
(0.003)\end{array}$ & $\begin{array}{c}\mathbf{0 . 0 3 8} \\
(0.003)\end{array}$ & $\begin{array}{l}-0.081 \\
(1.817)\end{array}$ & $\begin{array}{l}-3.439 \\
(1.657)\end{array}$ & $\begin{array}{c}7.588 \\
(1.899)\end{array}$ \\
\hline DE0001135275 & $\begin{array}{c}\mathbf{0 . 0 8 6} \\
(0.005)\end{array}$ & $\begin{array}{c}\mathbf{0 . 0 9 0} \\
(0.005)\end{array}$ & $\begin{array}{c}\mathbf{0 . 1 1 9} \\
(0.006)\end{array}$ & $\begin{array}{l}\mathbf{- 1 5 . 1 0 1} \\
(3.855)\end{array}$ & $\begin{array}{c}5.516 \\
(3.835)\end{array}$ & $\begin{array}{l}\mathbf{2 4 . 6 8 2} \\
(3.907)\end{array}$ \\
\hline FR0108354806 & $\begin{array}{c}\mathbf{0 . 0 2 5} \\
(0.003)\end{array}$ & $\begin{array}{c}\mathbf{0 . 0 2 8} \\
(0.003)\end{array}$ & $\begin{array}{c}\mathbf{0 . 0 3 0} \\
(0.004)\end{array}$ & $\begin{array}{l}\mathbf{- 8 . 0 5 1} \\
(2.497)\end{array}$ & $\begin{array}{c}0.281 \\
(2.626)\end{array}$ & $\begin{array}{l}13.774 \\
(4.089)\end{array}$ \\
\hline FR0010288357 & $\begin{array}{c}\mathbf{0 . 0 2 7} \\
(0.003)\end{array}$ & $\begin{array}{c}\mathbf{0 . 0 3 1} \\
(0.003)\end{array}$ & $\begin{array}{c}\mathbf{0 . 0 6 1} \\
(0.003)\end{array}$ & $\begin{array}{l}\mathbf{2 0 . 6 4 5} \\
(6.839)\end{array}$ & $\begin{array}{l}\mathbf{- 4 8 . 4 5 0} \\
(7.020)\end{array}$ & $\begin{array}{c}7.914 \\
(8.328)\end{array}$ \\
\hline FR0010070060 & $\begin{array}{c}\mathbf{0 . 0 8 6} \\
(0.008)\end{array}$ & $\begin{array}{c}\mathbf{0 . 1 0 9} \\
(0.008)\end{array}$ & $\begin{array}{c}\mathbf{0 . 1 2 9} \\
(0.009)\end{array}$ & $\begin{array}{l}\mathbf{- 1 0 . 5 5 4} \\
(3.582)\end{array}$ & $\begin{array}{c}3.478 \\
(3.626)\end{array}$ & $\begin{array}{c}\mathbf{1 0 . 7 2 4} \\
(3.7169)\end{array}$ \\
\hline IT0004026297 & $\begin{array}{c}\mathbf{0 . 0 1 9} \\
(0.001)\end{array}$ & 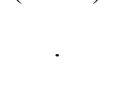 & $\begin{array}{c}\mathbf{0 . 0 2 1} \\
(0.001)\end{array}$ & $\begin{array}{l}23.641 \\
(7.263)\end{array}$ & ( & $\begin{array}{c}-72.316 \\
(7.515)\end{array}$ \\
\hline IT0004019581 & $\begin{array}{c}\mathbf{0 . 0 2 1} \\
(0.001)\end{array}$ & $\cdot$ & $\begin{array}{c}\mathbf{0 . 0 3 2} \\
(0.001)\end{array}$ & $\begin{array}{l}\mathbf{- 1 7 . 5 7 5} \\
(9.769)\end{array}$ & $\cdot$ & $\begin{array}{l}32.987 \\
(9.344)\end{array}$ \\
\hline IT0003934657 & $\begin{array}{r}\mathbf{0 . 0 6 5} \\
(0.003) \\
\end{array}$ & $\begin{array}{c}\mathbf{0 . 0 9 1} \\
(0.004) \\
\end{array}$ & $\begin{array}{c}\mathbf{0 . 1 2 7} \\
(0.004) \\
\end{array}$ & $\begin{array}{c}-23.961 \\
(9.193) \\
\end{array}$ & $\begin{array}{c}9.398 \\
(9.224)\end{array}$ & $\begin{array}{l}29.213 \\
(9.146) \\
\end{array}$ \\
\hline Panel B & Restriction & he mean & $\begin{array}{c}\text { Granger } \\
\text { Causality }\end{array}$ & Restricti & the mean & $\begin{array}{c}\text { Granger } \\
\text { Causality }\end{array}$ \\
\hline DE0001141489 & $\mu_{1}=\mu_{2}=\mu_{33}$ & {$[0.007]$} & {$[0.039]$} & $\mu_{1}=-\mu_{3}$ & {$[0.000]$} & {$[0.000]$} \\
\hline DE0001135291 & $\mu_{1}=\mu_{2}=\mu_{3}$ & {$[0.000]$} & {$[0.000]$} & $\mu_{1}=-\mu_{3}$ & {$[0.212]$} & {$[0.036]$} \\
\hline DE0001135275 & $\mu_{1}=\mu_{2}=\mu_{3}$ & {$[0.000]$} & {$[0.046]$} & $\mu_{1}=-\mu_{3}$ & {$[0.211]$} & {$[0.000]$} \\
\hline FR0108354806 & $\mu_{1}=\mu_{2}=\mu_{3}$ & {$[0.199]$} & {$[0.044]$} & $\mu_{1}=-\mu_{3}$ & {$[0.334]$} & {$[0.256]$} \\
\hline FR0010288357 & $\mu_{1}=\mu_{2}=\mu_{3}$ & {$[0.000]$} & {$[0.000]$} & $\mu_{1}=-\mu_{3}$ & {$[0.000]$} & {$[0.000]$} \\
\hline FR0010070060 & $\mu_{1}=\mu_{2}=\mu_{3}$ & {$[0.000]$} & {$[0.848]$} & $\mu_{1}=-\mu_{3}$ & {$[0.980]$} & {$[0.011]$} \\
\hline IT0004026297 & $\mu_{1}=\mu_{3}$ & {$[0.000]$} & {$[0.009]$} & $\mu_{1}=-\mu_{3}$ & {$[0.000]$} & {$[0.246]$} \\
\hline IT0004019581 & $\mu_{1}=\mu_{3}$ & {$[0.000]$} & {$[0.000]$} & $\mu_{1}=-\mu_{3}$ & {$[0.000]$} & {$[0.000]$} \\
\hline IT0003934657 & $\mu_{1}=\mu_{2}=\mu_{3}$ & {$[0.000]$} & {$[0.000]$} & $\mu_{1}=-\mu_{3}$ & {$[0.000]$} & {$[0.000]$} \\
\hline
\end{tabular}

Note. In Panel A, regime-dependent mean values $\left(\mu_{j}, j=1,2,3\right)$ statistically significant at the 5 percent significance level (or better) are reported in bold. Estimated standard errors are in parentheses. In Panel B, restriction on the mean in the quoted spread (trading imbalances) equation tests the null of equal mean (in absolute values) across regimes. Granger Causality in the quoted spread (trading imbalances) equation tests the null that past values of trading imbalances (quoted spreads) do not affect current values of the dependent variable. $p$-values are in squared brackets. Market codes for German, French and Italian bonds are DE..., FR.. and IT..., respectively. For each market, the first, the second, and the third code refers to the 5, 10 and 30-year bond, respectively. 
Table 6 - Ordered probit estimation results

\begin{tabular}{|c|c|c|c|c|}
\hline & \multirow{2}{*}{ Pooled-ORM (A) } & \multirow{2}{*}{ RE-ORM (B) } & \multicolumn{2}{|c|}{ Generalized RE-ORM (C) } \\
\hline & & & Equation 1 & Equation 2 \\
\hline \multirow{2}{*}{ repo } & -0.376 & -0.432 & $-0.731 *$ & -0.128 \\
\hline & $(0.369)$ & $(0.375)$ & $(0.428)$ & $(0.429)$ \\
\hline \multirow{2}{*}{ mktr } & $0.245 * *$ & $0.302 * *$ & \multicolumn{2}{|c|}{$0.297 * *$} \\
\hline & $(0.118)$ & $(0.119)$ & \multicolumn{2}{|c|}{$(0.120)$} \\
\hline \multirow{2}{*}{ mktv } & $-0.987 * *$ & $-1.006^{* *}$ & \multicolumn{2}{|c|}{$-1.013 * *$} \\
\hline & $(0.417)$ & $(0.419)$ & \multicolumn{2}{|c|}{$(0.419)$} \\
\hline \multirow{2}{*}{$s t k v$} & 0.131 & 0.147 & $-0.356^{*}$ & $0.523 * * *$ \\
\hline & $(0.166)$ & $(0.170)$ & $(0.196)$ & $(0.187)$ \\
\hline \multirow{2}{*}{ indp } & -0.181 & -0.164 & $-0.312 *$ & 0.006 \\
\hline & $(0.135)$ & $(0.135)$ & $(0.164)$ & $(0.174)$ \\
\hline \multirow{2}{*}{ infl } & -0.070 & -0.044 & -0.084 & -0.018 \\
\hline & $(0.147)$ & $(0.153)$ & $(0.200)$ & $(0.166)$ \\
\hline \multirow{2}{*}{ unem } & $0.074 *$ & $0.073 *$ & 0.050 & $0.115^{*}$ \\
\hline & $(0.044)$ & $(0.044)$ & $(0.048)$ & $(0.069)$ \\
\hline \multirow{2}{*}{ malf } & $0.071 * *$ & $0.062 *$ & 0.045 & $0.073 *$ \\
\hline & $(0.036)$ & $(0.036)$ & $(0.044)$ & $(0.040)$ \\
\hline \multirow{2}{*}{$\rho$} & & $0.430 * * *$ & \multirow{2}{*}{\multicolumn{2}{|c|}{$\begin{array}{c}0.434 * * * \\
(0.044)\end{array}$}} \\
\hline & . & $(0.044)$ & & \\
\hline Observations & 1417 & 1417 & \multicolumn{2}{|c|}{1417} \\
\hline$L L$ & -1525.2 & -1465.2 & \multicolumn{2}{|c|}{-1450.6} \\
\hline$\gamma^{2}$ & 38.47 (12) & 42.65 (12) & \multicolumn{2}{|c|}{$102.53(18)$} \\
\hline$\chi$ & {$[0.000]$} & {$[0.000]$} & \multicolumn{2}{|c|}{$[0.000]$} \\
\hline$A I C$ & 3078.4 & 2960.5 & \multicolumn{2}{|c|}{2943.2} \\
\hline$\gamma^{2}$ - PRA & & & \multicolumn{2}{|c|}{$29.27(6)$} \\
\hline A & . & . & \multicolumn{2}{|c|}{$[0.000]$} \\
\hline
\end{tabular}

Note. The dependent variable is equal to 2,1 and 0 when the average daily probability of being in the high, intermediate and low liquidity regime, respectively, is the highest among the probabilities associated with the various states. Country and maturity dummies, albeit included among the regressors, are omitted for ease of exposition. Single, double and triple stars indicate significance at the 10,5 and 1 percent levels, respectively. Standard errors are in parentheses. LL and AIC indicate the value of the log-likelihood function and the Akaike Information Criteria, respectively. $\chi^{2}$ is the test statistics for the joint impact of the covariates on the dependent variable. $\chi^{2}$-PRA is the test statistics for symmetric impact of the covariates on the dependent variable across categories. Degrees of freedom are in parentheses, while p-values in square brackets. repo is the difference between bond specific spot next repo rates and the Euro short term repo (middle rate) by the ECB. mktr is the difference between HP-filtered log-prices of the country-specific EuroMTS index and of the European aggregate EuroMTS index (with the same maturity of the bond). mktv is the absolute value of the difference between the first differences of the log-prices of the country-specific EuroMTS index and of the European aggregate EuroMTS index (with the same maturity of the bond). stkv is the absolute value of the difference between the first differences of the log-prices of the country-specific stock index and of the DJ Euro 600 index. infl, indp and unem are standardised scheduled news, given by the difference between the value announced and the median of survey expectation of announcement divided by the sample standard deviation of that difference, on year-on-year changes of inflation, industrial production and unemployment, respectively. malf is the standardised value (i.e. the difference between actual values and the sample average divided by the sample standard deviation) of the amount (in EUR millions) of volumes for marginal lending facility. See Appendix B for details on data sources. 


\section{Figures}

Figure 1 - Simulated probabilities: baseline generalised RE-ORM
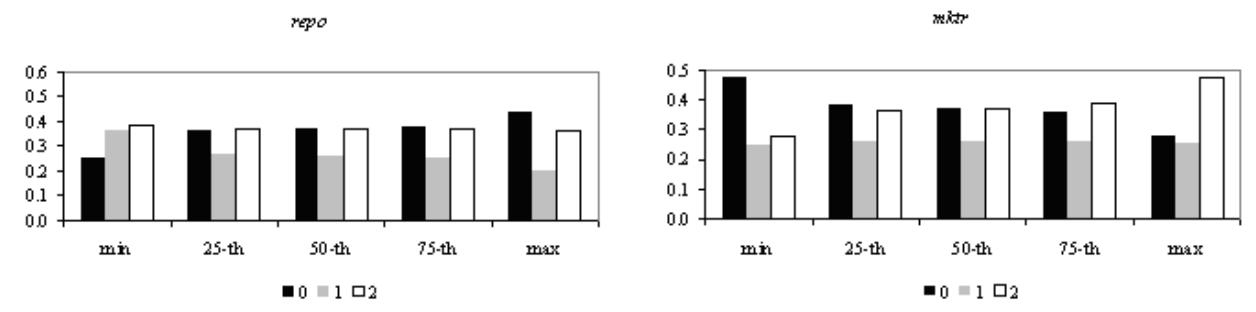

w k t

stkw
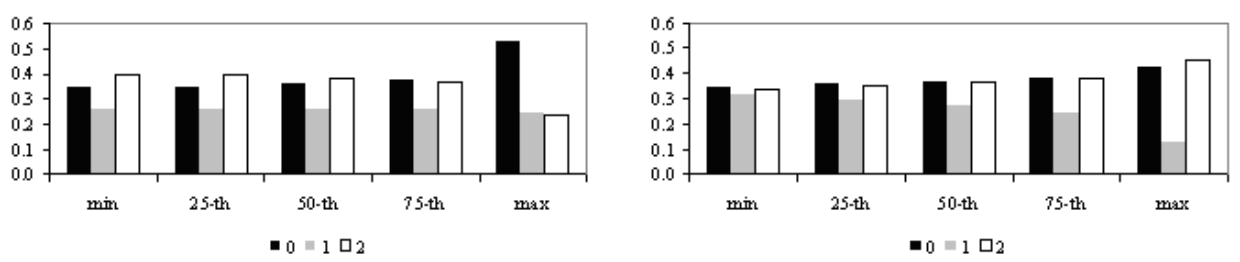

incop

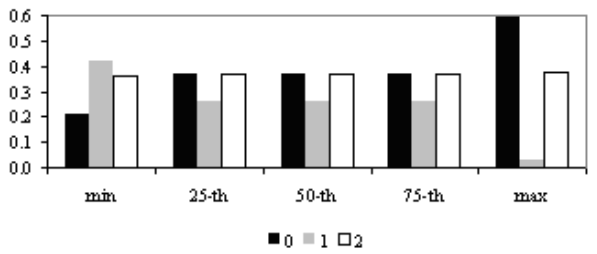

unem

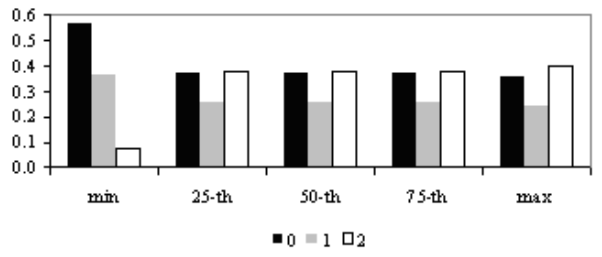

mais

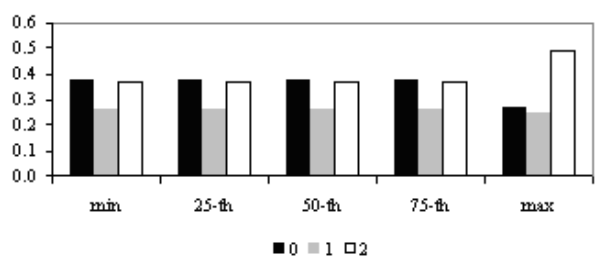

Note. In each graph, the vertical axis indicates the probability associated to a certain state of liquidity. Black, grey and white bars refer to $\operatorname{Pr}\left(r_{i t}=0\right), \operatorname{Pr}\left(r_{i t}=1\right)$ and $\operatorname{Pr}\left(r_{i t}=2\right)$, respectively. The horizontal axis reports these probabilities, computed at the minimum as well as at the first quartile, at the median, at the third quartile and at the maximum value of the distribution of each predictor, ceteris paribus. See notes in Table 6 for details on the predictors. 